\title{
INVESTIGATION ON FLEXURAL BEHAVIOUR OF GLASS BEAMS INCORPORATING STAINLESS STEEL REINFORCEMENT
}

\author{
S.Subraja ${ }^{1}$, C.Nivetha ${ }^{2}$, R.Sowmya ${ }^{3}$, S.Bharath ${ }^{4}$ \\ ${ }^{1}$ Assistant professor, Department of civil engineering, AVIT, Tamil Nadu, India \\ ${ }^{2}$ Assistant professor, Department of civil engineering, AVIT, Tamil Nadu, India \\ ${ }^{3}$ Assistant professor, Department of civil engineering, AVIT, Tamil Nadu, India \\ ${ }^{4}$ Assistant professor, Department of civil engineering, AVIT, Tamil Nadu, India
}

\begin{abstract}
Glass has been used only as a non structural element in the past centuries. Nowadays, its use has been changed from non-structural use to structural use which brings up light into the building due to its transparency and saves energy to the eco-friendly world and gives aesthetic view. The glass beams are used as a supporting member of the glass panels in the roof structures. Glass is a brittle material and has high compressive strength compared to that of concrete and has low tensile strength similar to concrete. To develop its tensile strength, different types of reinforcement can be provided in the tensile zone of glass beams. The reinforcement for these type of composite glass beams are made of materials like steel, wood, etc. in the form of hollow tube section or solid section. This study presents the experimental work of eight glass beams of size $550 \mathrm{~mm}$ X $21.5 \mathrm{~mm}$ X $70 \mathrm{~mm}$ of two glass type (annealed glass and toughened glass) with varying reinforcement percentage. The stainless steel plates are provided at the bottom of the glass beams in the form of a channel as reinforcement. Load deflection response of glass beams is studied.
\end{abstract}

Keywords: Laminated glass, $P V B$, Strength ,Reinforcement

\section{INTRODUCTION}

Glass is no longer considered as a non-structural element. Now it has been turned to use as the structural element which serves as a good building material to carry load. Glass is a brittle material that is weak in tension because of its non-crystalline molecular structure. The restrictions in the use of glass, due to the intrinsic brittleness and to the danger of the fall of fragments after breakage were partially overcome with the use of laminated glass [1]. When glass is stressed beyond its strength limit, breakage will occurs immediately without warning, unlike steel or alloy of steel where plastic mechanism can be formed [2].As Glass is a brittle material and that stress in glass cannot be re-distributed and failure is assumed once crack occurs . To enhance its flexural strength,different types of reinforcement is provided in the glass beams was explained in the literature [3],[4].Effect of temperature, thermal cycling and humidity on structural response on SG laminated reinforced beams was reported in literature [5].

\section{BEHAVIOUR OF GLASS}

The main problem of constructing with glass is the absence of reserve load bearing capacity after initial failure. When a single crack appears on glass, then glass attains its failure load. Steel beam will yield noticeably upon overloading and in this way will warn before collapse. This warning before collapse and a residual strength after initial failure is safe failure behaviour. Glass has brittle failure mechanism and no built-in warning system and therefore no safe failure behaviour. When overloaded, it will fail suddenly and lose its integrity. There will be no residual load bearing capacity. In current glass structures, several methods are used to obtain a glass structure with an appropriate level of reliability: the use of toughened glass and the use of laminates. However, these methods lead to an uneconomical structure and only limited safety. Safe failure behaviour is obtained by bonding stainless steel section in the tensile zone of the glass beam. Small stainless section placed in the tensile zone will act as the reinforcement. On over loading beyond the load carrying capacity the glass starts to crack but the compression zone of glass and reinforcement combine together to still carry the load.

\section{TEST TO FIND THE STRENGTH OF GLASS}

In practice, glazing panels are typically subject to out-of-plane bending when wind pressure is applied and when the load transferred to the beam, the beam also acts subjected to the out of-plane bending. Several test methods have been developed to examine the bending strength of glass. These test methods can be classified as (i) uni-axial bending tests and (ii) biaxial bending tests. With uni-axial bending test specimens are supported on two parallel sides and subject to one or two concentrated line loads causing bending in one direction. The advantage of this test method is that only one principal stress is developed at all locations in the glass specimen. Hence, possible influences by other (minor) principal stress have been neglected. The uni-axial bending test with two concentrated line loads is also known as four-point bending test shown in figure 1 . 


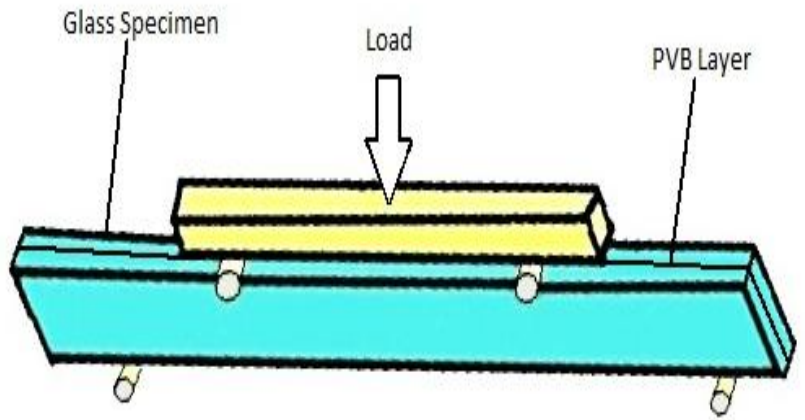

Fig-1:Four-point bending test

\section{TEST SETUP}

The eight specimens are tested by placing the glass in the vertical position as that it is to be placed in the field to transfer the point load in by the spider arms. Among eight specimens, four specimens are annealed glass type and other four specimens are toughened type. Among four specimen of one type of glass, one specimen is of unreinforced and other three specimens are reinforced in the tensile zone to prevent the brittle failure with varying thickness of stainless steel plates. The load is appliedat an interval of $0.1 \mathrm{kN}$.

\section{TEST RESULTS OF SPECIMENS}

Two points loading is applied in the Glass beam in one third of the effective span. The glass beams used for the entire test have same geometry (550 mm x $21.52 \mathrm{~mm} \times 70 \mathrm{~mm})$. The Glass beams are reinforced by the stainless steel. The stainless steel plates are folded in the form of channel of $22 \mathrm{~mm} \times 10 \mathrm{~mm}$ and varying thickness

. Table -1: Maximum load carrying capacity

\begin{tabular}{|c|c|c|}
\hline Glass type & $\begin{array}{c}\text { Reinforcement } \\
\text { percentage }\end{array}$ & $\begin{array}{c}\text { Maximum load } \\
\text { (KN) }\end{array}$ \\
\hline Annealed & $0 \%$ & 5.9 \\
\hline Annealed & $1.00 \%$ & 10.5 \\
\hline Annealed & $3.35 \%$ & 17.2 \\
\hline Annealed & $4.18 \%$ & 20 \\
\hline Toughened & $0 \%$ & 19.5 \\
\hline Toughened & $1.00 \%$ & 23.3 \\
\hline Toughened & $4.18 \%$ & 29.1 \\
\hline & & \\
\hline
\end{tabular}

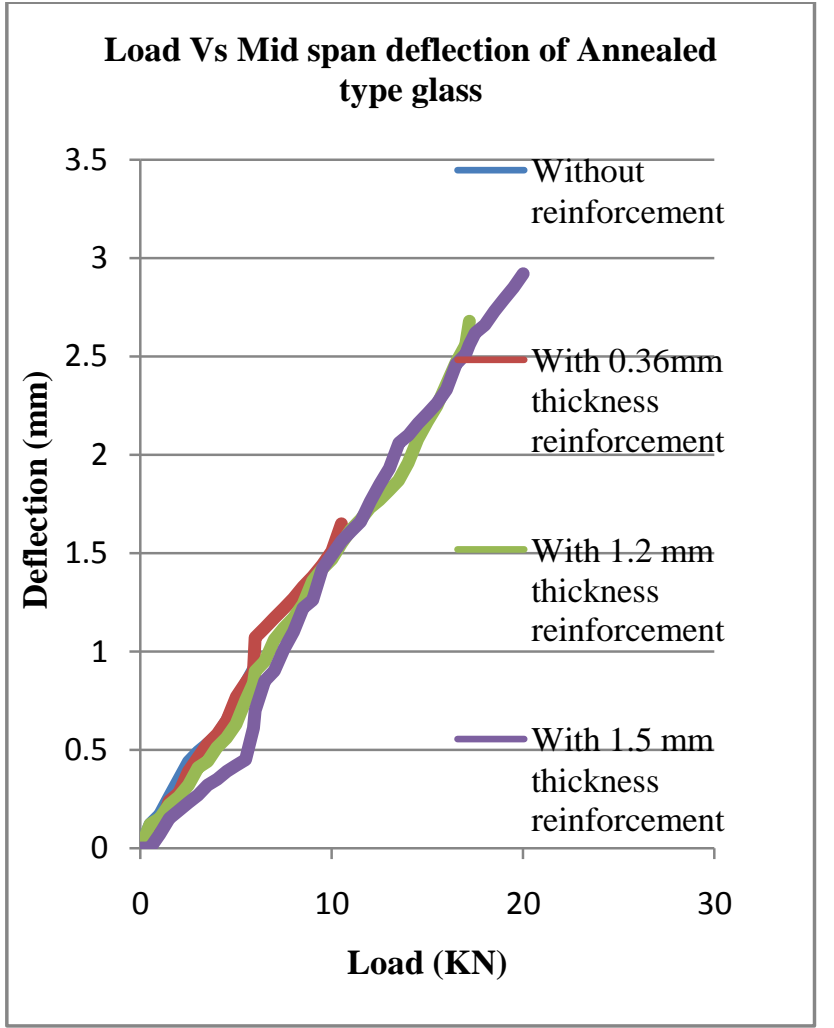

Fig -2: Load Vs Mid span deflection of Annealed type glass

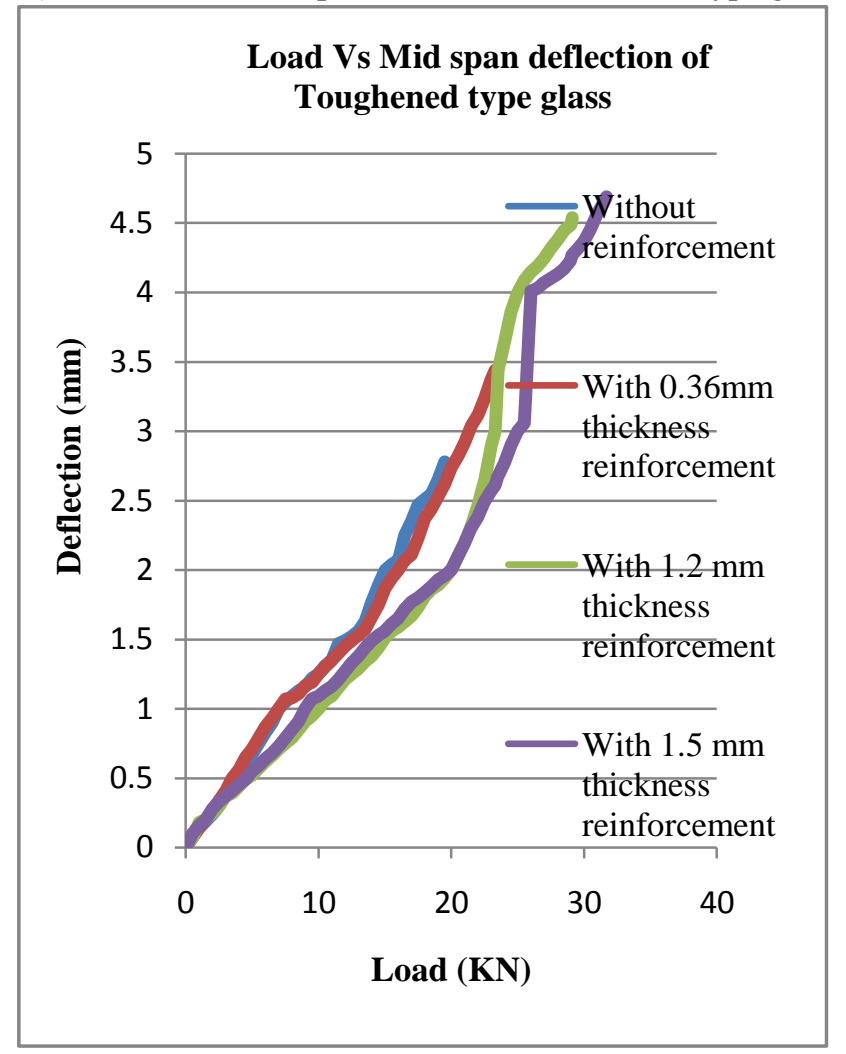

Fig -3: Load Vs Mid span deflection of Toughened type glass 


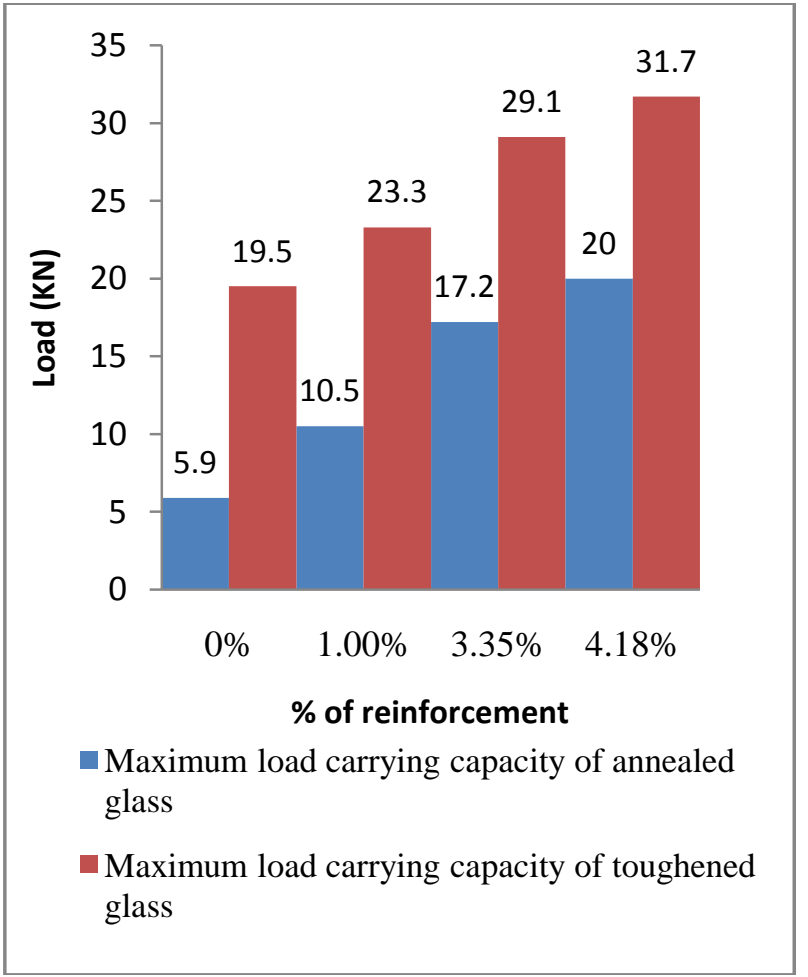

Chart -1: Maximum load carrying capacity

\section{FAILURE PATTERN OF ANNEALED GLASS}

The annealed glass without reinforcement fails unexpectedly without any warnings and its load carrying capacity suddenly drops to zero shown in figure 5 The glass began to fail at the failure load and glass particles spreads in around area. The glass still remains in the support.Glass beams with reinforcement of $1.00 \%$ starts to buckle and separated from the glass at the failure point. Glass beams with reinforcement of $3.35 \%$ and $4.18 \%$ slip failure occurs.

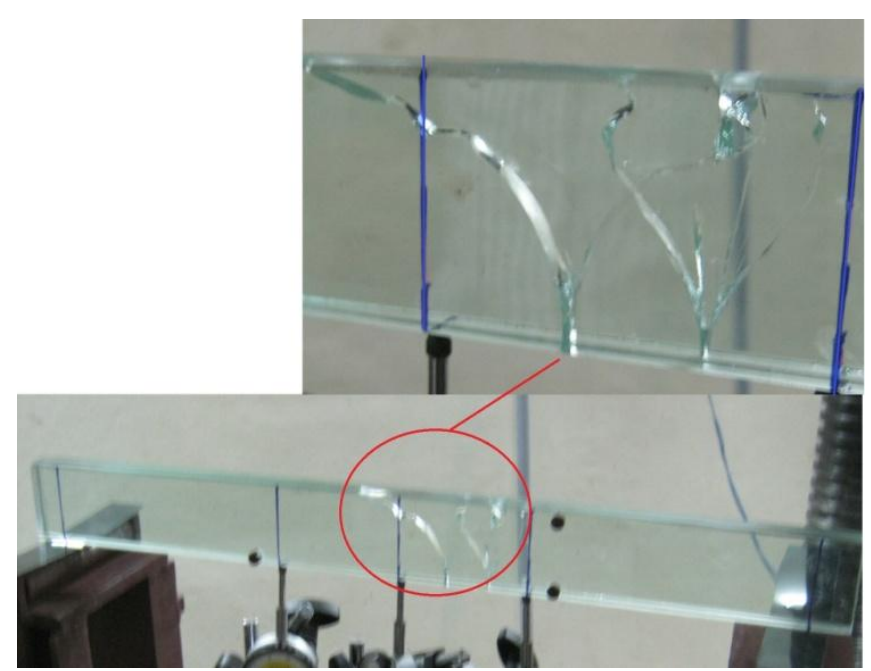

Fig - 4 :Failure pattern of unreinforced annealed glass

\section{FAILURE PATTERN OF TOUGHENED}

\section{GLASS}

The toughened glass without reinforcement fails rapidly without any warnings and its load carrying capacity suddenly drops to zero in figure 6 The glass at the loading point starts to fail at the failure load and glass beam slips from the support.The glass fails suddenly when the loading steel comes in contact with the glass. Reinforced glass beams do not slip from the support .Glass beams with reinforcement of $1.00 \%$ stainless steel plate starts to buckle and detached from the glass at the failure point of the glass. The glass beams with reinforcement of $3.35 \%$ and $4.18 \%$ slip failure occurs.

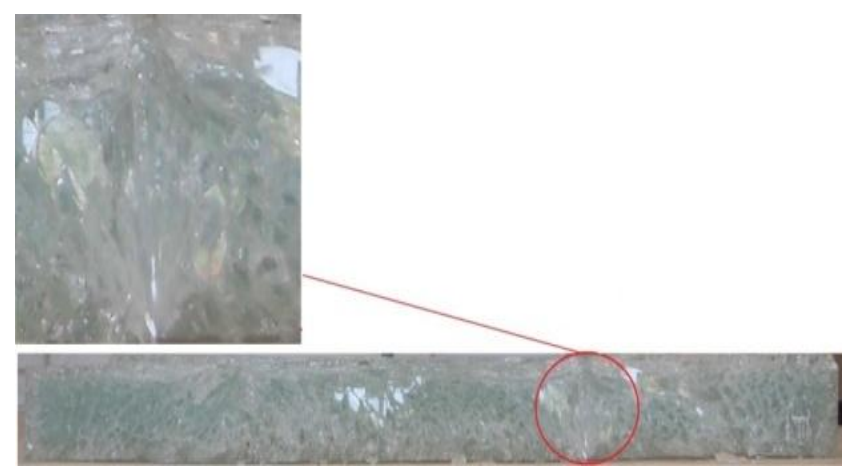

Fig - 5 :Failure pattern of unreinforced toughened glass

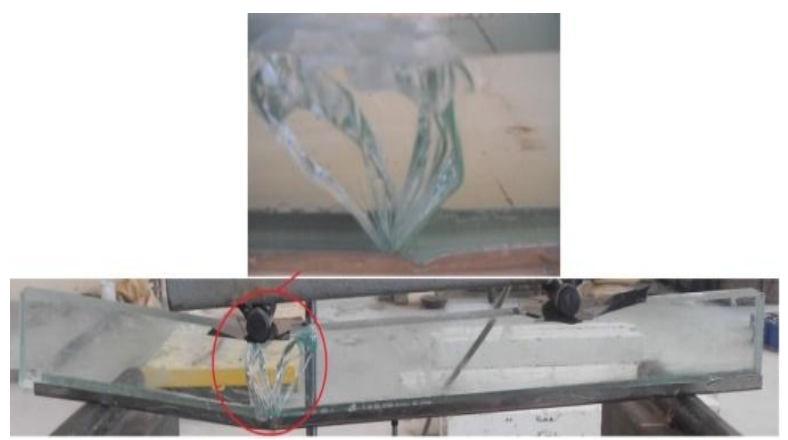

(a)

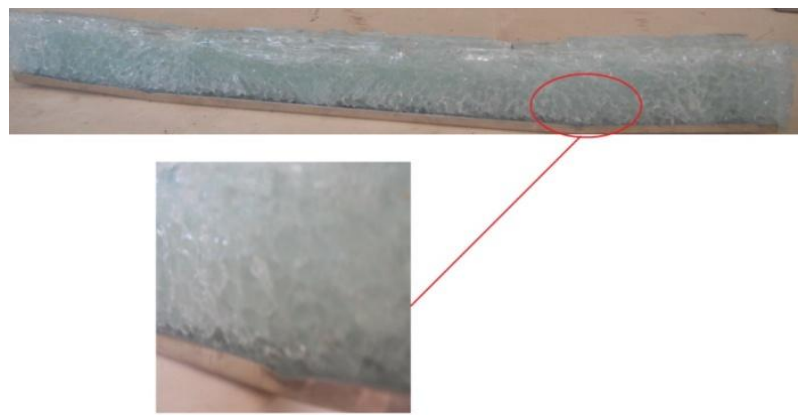

(b)

Fig -6 : Failure pattern of glass beam for $1.00 \%$ stainless steel reinforcement

(a) Annealed glass (b) Toughened glass 

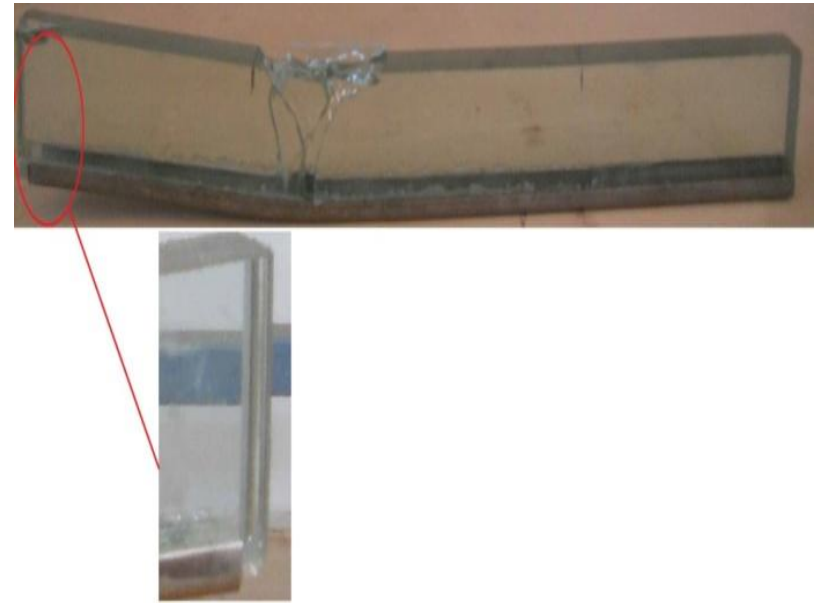

(a)

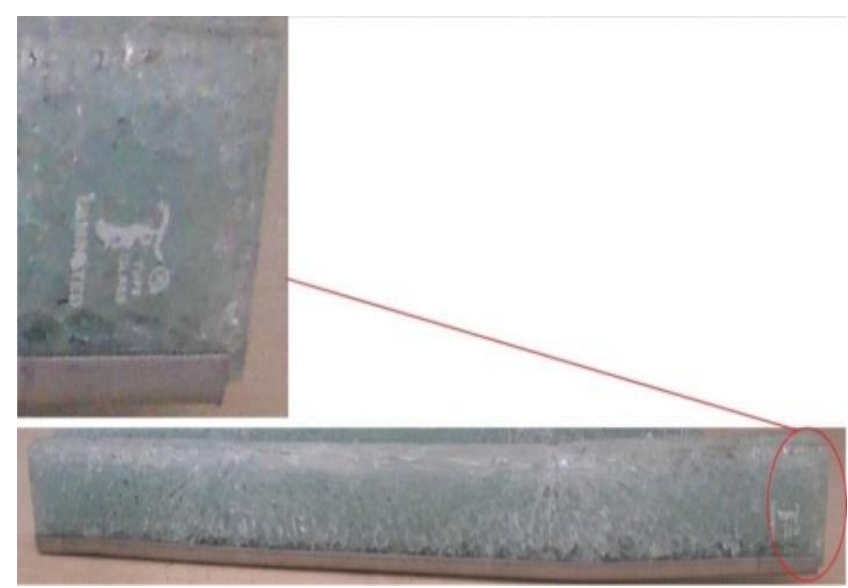

(b)

Fig -7 : Failure pattern of glass beam with $3.35 \%$ and $4.18 \%$ stainless steel reinforcement

(a) Annealed glass (b) Toughened glass

\section{CONCLUSIONS}

- In this paper flexural behaviour of laminated annealed and laminated toughened glass beams samples are tested by varying the reinforcement percentage.

- The strength of toughened glass is $58.5 \%$ more than that of annealed glass.

- The toughened glass without reinforcement is not suitable to use in the structure as it spreads over the area as the whole by displacing from the support and it reduces the safety .

- As on reinforcing the toughened glass, it does not gets spread and it resumes in the support.

- Load carrying capacity of the reinforced glass beams are higher compared to unreinforced glass beam.

- Initial height of the uncracked compression zone increases with increase of percentage of the reinforcement.

- Ductility of the glass beams is improved by providing reinforcement in the tensile zone of the glass beams .

- Load carrying capacity of the reinforced glass beams increases with increase in percentage of reinforcement .

\section{REFERENCES}

[1]. BriccoliBati.B., Ranocchiai.G.,Reale.C. and Rovero.L. (2013) 'Time-Dependent Behaviour of Laminated Glass', ASCE, Journal of Materials in Civil Engineering, Vol. 22, No. 4,pp.389 -396.

[2]. Christian Louter ,Anne van de Graaf, Jan Rots.(2010) 'Modeling the Structural Response of Reinforced Glass Beams using an SLA Scheme', Challenging Glass 2 Conference on Architectural and Structural Applications of Glass,Bos, Louter, Veer eds. TU Delft, TheNetherlands.

[3]. Christian Louter,Calvin Leung, Henk Kolstein, Jan Vamberský (2010), 'Structural Glass Beams with Embedded Glass Fibre Reinforcement' Challenging Glass 2 Conference on Architectural and Structural Applications of Glass, Bos, Louter, Veer (Eds.), TU Delft, The Netherlands. [4]. Christian Louter, Jan Belis, FreekBos, Dieter Callewaert, Frederik Veer (2010). 'Experimental investigation of the temperature effect on the structural response of SG-laminated reinforced glass beams', Engineering Structures 32 pp 1590-1599.

[5]. Christian Louter, Jan Belis , Frederic Veer, Jean-Paul Lebet, (2012) 'Durability of SG-laminated reinforced glass beams: Effects of temperature,thermal cycling, humidity and load-duration', Construction and Building Materials 27, pp 280-292.

[6]. MeenuTeotia ,Soni .R.K (2012), 'Polymer interlayers for glass lamination ', International journal of science and research , Vol 3, No. 8, pp 1264 -1269.

[7]. Slivansky .M(2012),' Experimental verification of the resistance of glass beams ', Slovak journal of civil engineering, Vol 20, No.1, PP 21-28 .

[8]. Slivansky .M , (2012),' Theoretical verification of the reinforced glass beams',Procedia Engineering, Vol 40 ,pp $417-422$.

[9]. Scott Norville .H , (1998 ),'Laminated glass :Glazing material for all conditions ',pp 1-7.

[10]. Stephen J .Bennison, Maria HX Qin and Phillip S. Davies . (2008),' High- Performance laminated glass for structurally efficient glazing',Innovative light - weight structures and sustainable facades ,pp $1-12$.

[11]. Jun Xu , Yueting Sun , Bohan Liu , Mengyi Zhu , Xuefeng Yao, Yuan Yan, Yibing Li , Xi Chen (2011),' Experimental and macroscopic investigation of dynamic crack patterns in PVB laminated glass sheets subjected to light - weight impact ', Engineering Failure Analysis , pp 1605-1612

[12]. JelenaSavic , DanijelaDuric- Mijovic , VeliborkaBogdanovic , (2013) ,'Architectural glass : Types,performance and legislation ', Architecture and civil engineering, Vol. 11 , No.1,pp 35- 45 .

[13]. Lynn Beason ,Terry L .Kohutek, and Joseph M. Bracci (1998) ,'Basis for ASTM E 1300 Annealed glass thickness selection charts ',Journal of structural engineering, pp $215-221$.

[14]. Nielsen .J.H \&Olesen .J.F (2010) ,'Post -crack capacity of mechanically reinforced glass beams ',Fracture mechanics of concrete and concrete structures pp 370 -376. [15]. Timmel .M ,Kolling .S , Osterrieder .P ,Du Bois .P.A (2007) ,'A finite element modal for impact simulation with 
laminated glass ',International journal of impact engineering pp $1465-1478$.

[16]. Pyttel .T ,Liebertz .H , Cai .J (2011) ),'Failure criterion for laminated glass under impact loading and its application in finite element simulation ',International Journal of Impact Engineering pp $252-263$.

[17]. Leon Jacob ,'Understanding the versatility of laminated safety glass as a glazing product of the future ' $p p$ $202-204$.

[18]. Veer .F.A , Louter .P.C and Bos .F.P .(2008), 'The strength of annealed, heat-strengthened and fully tempered float glass ',Fatigue \& Fracture Of Engineering Materials \& Structures pp $18-25$. 